\title{
Comparative Study of Dexmedetomidine and Fentanyl as an Adjuvant to Epidural Bupivacaine for Post-operative Pain Relief in Hepato-biliary Pancreatic Surgery
}

\author{
*R Ahmed ${ }^{1}$, MSA Shaheen ${ }^{2}$, PK Sarker ${ }^{3}$, SP Roy ${ }^{4}$, MNA Alam ${ }^{5}$
}

\begin{abstract}
Background: Postoperative pain responsible for neurohumoral changes which may cause various organ dysfunctions, prolong hospitalization and convalescence. Epidural analgesia confers excellent pain relief and complete dynamic analgesia leading to a substantial reduction in the surgical stress response.
\end{abstract}

Objectives: The aim of the study was to compare the postoperative analgesic effect of dexmedetomidine and fentanyl as an adjuvant to epidural bupivacaine in adult patients undergoing hepatobiliary pancreatic surgery.

Material and method: Eighty(80) patients were selected in the pre anaesthetic checkup room who were going to be operated for hepatobiliary pancreatic disorders. Each patient in group $\mathrm{D}$ (Dexmedetomidine group): Dexmedetomidine $2 \mathrm{ml}(100 \mu \mathrm{gm})$ was mixed with $48 \mathrm{ml}$ bupivacaine $0.125 \%$ in a syringe $50 \mathrm{ml}$ and infused epidurally @ $4 \mathrm{ml} / \mathrm{hr}$. for the postoperative 48 hours. Group F (fentanyl group): Fentanyl $2 \mathrm{ml}(100 \mu \mathrm{gm})$ was mixed with $48 \mathrm{ml}$ bupivacaine $0.125 \%$ in a syringe $50 \mathrm{ml}$ and infused epidurally @ 4ml $/ \mathrm{hr}$. for the postoperative 48 hours.

Results: The quality of analgesia was almost similar with dexmedetomidine and fentanyl group but perioperative haemodynamic stability was more in dexmedetomidine group than fentanyl group $(\mathrm{p}=<0.05)$. The incidence of post-operative nausea and vomiting, pruritus, urinary retention and respiratory depression significantly lower with dexmedetomidine compared to fentanyl group $(\mathrm{p}=<0.05)$.

Conclusion: Dexmedetomidine is an ideal adjuvant to epidural bupivacaine for postoperative analgesia compared to fentanyl in patients undergoing hepatobiliary pancreatic surgery.

Key Words: Dexmedetomidine, fentanyl, epidural bupivacaine, hepatobiliary pancreatic surgery.

\section{Introduction}

Pain is an unpleasant sensory and emotional experience associated with actual or potential tissue damage or described in terms of such damage. ${ }^{1}$ Postoperative pain, is typically associated with neuro-endocrine stress response that is proportional to pain intensity. Many patients, however, continues to experience inadequate pain relief. $^{2}$ Despite improvements in analgesic delivery, several recent surveys have found that up to $80 \%$ of patients report

moderate to severe pain after surgery. ${ }^{3,4,5}$

The postoperative pain scores are lowered by using multimodal analgesia and continuous epidural analgesia. ${ }^{6}$ Opioid and local anaesthetic infusion by an epidural catheter is widely used as a postoperative pain management method after major abdominal surgeries. ${ }^{7}$ There are several methods now a days to provide sufficient analgesia. The

IDr. Raju Ahmed, Assistant Professor, Department of Anaesthesiology, Ibrahim Cardiac Hospital and Research Institute Email: araju1287@gmail.com, Mobile: +8801712590744

${ }^{2} \mathrm{Dr}$. Md. Shafiul Alam Shaheen, Assistant Professor, Department of Anaesthesiology \& Surgical ICU, Ibrahim Medical College \& BIRDEM General Hospital

${ }^{3}$ Dr. Pradip Kumar Sarker, Assistant Professor, Department of Cardiac Anaesthesiology, Ibrahim Cardiac Hospital and Research Institute

${ }^{4}$ Dr. Siba Pada Roy, Associate Consultant, Department of Cardiac Anaesthesiology, Ibrahim Cardiac Hospital and Research Institute

5Prof. Mohammad Noor A Alam, Professor, Department of Surgery, Ibrahim Medical College \& BIRDEM General Hospital

*Corresponding Author

Date of submission: 20.04.2019 Date of acceptance: 23.05.2019

AKMMC J 2019; 10(2) : 143-149 
agents which cause less side effects but better quality of analgesia is more valuable.

Epidural opioids with or without local anaesthetics provides a postoperative pain relief, but it is associated with many side effects. Opioids like fentanyl have been used traditionally as an adjunct for epidural administration in combination with a lower dose of local anaesthetic to achieve the desired anaesthetic effect. ${ }^{8}$ Fentanyl acts as an agonist at $\mu$-opioid receptors to enhance the analgesia, it is 100 times more potent than morphine.

Dexmedetomidine is a highly selective $\alpha_{2}$ adrenergic receptor agonist, and it has a sedative, anxiolytic, analgesic, antihypertensive and sympatholytic properties. ${ }^{9}$ It improves the quality of perioperative anaesthesia and analgesia. ${ }^{10}$ Dexmedetomidine does cause a manageable hypotension and bradycardia but the striking feature of this drug is the lack of opioid-relate side effects like respiratory depression, pruritis, nausea, and vomiting. ${ }^{11,12}$

Our goal in this prospective, single blind, randomized study was to compare the postoperative analgesic effect of dexmedetomidine and fentanyl as an adjuvant to continuous epidural bupivacaine with their side effects in adult patients undergoing hepatobiliary pancreatic surgeries.

\section{Materials \& Methods}

This randomized single-blind study was conducted from $1^{\text {st }}$ January, 2015 to $31^{\text {st }}$ December, 2016 at the department of Anaesthesiology and Surgical ICU, BIRDEM General Hospital, Shahbagh, Dhaka, Bangladesh. After institutional ethical committee approval and informed written consent, a total number of 80 adult patients with ASA physical status I\&II scheduled for various elective hepatobiliary and pancreatic surgeries under combined anaesthesia (General plus Epidural) were enrolled in this study. All patients were reassured and the anaesthetic procedure was explained on the day before the operation. Intravenous access established in all patients in the operating room with base line arterial blood pressure (non-invasively) and heart rate obtained. Every patient was received an epidural block in the sitting position at the T8-9 or T9-10 level via 18 G Touhy needle. After epidural insertion each patient received $6-8 \mathrm{ml}$ $0.125 \%$ inj. Bupivacaine through epidural catheter. Each patient received General anaesthesia with induction dose of inj. Fentanyl 2 microgram $/ \mathrm{kg}$, inj. Propofol $2 \mathrm{mg} / \mathrm{kg}$ and muscle relaxant inj. Atracurium $0.5 \mathrm{mg} / \mathrm{kg}$. After induction, general anaesthesia was maintained by $60 \% \mathrm{~N}_{2} \mathrm{O}$ and $40 \%$ $\mathrm{O}_{2}$ and continuous infusion of Propofol @ $4 \mathrm{mg} / \mathrm{kg} / \mathrm{hr}$. - $6 \mathrm{mg} / \mathrm{kg} / \mathrm{hr}$. An incremental dose of muscle relaxant inj. Atracurium 1/4th of initial dose was given every 20 minutes interval. The base line blood pressure and heart rate were recorded from the same noninvasive monitor and cardiac rate and rhythm were also monitored from a continuous display of E.C.G from lead II.

After extubation patients were transferred to recovery room. Analgesia was given in the immediate postoperative period $(0 \mathrm{hr}$.) and they were divided into two groups 40 in each group randomly allocated by envelop method where Each patient in group $\mathrm{D}$ (Dexmedetomidine group): Dexmedetomidine $2 \mathrm{ml}(100 \mu \mathrm{g})$ was mixed with $48 \mathrm{ml}$ bupivacaine $0.125 \%$ in a syringe $50 \mathrm{ml}$ and infused epidurally@4ml/hr. for the postoperative 48 hours. Group F (fentanyl group): Fentanyl $2 \mathrm{ml}$ $(100 \mu \mathrm{g})$ was mixed with $48 \mathrm{ml}$ bupivacaine $0.125 \%$ in a syringe $50 \mathrm{ml}$ and infused epidurally @ 4ml/hr. for the postoperative 48 hours.

Visual analogue score (VAS), noninvasive blood pressure, heart rate, oxygen saturation, respiratory rate was recorded in every patient. All parameters were recorded at 0 hour, 1 hour, 3 hour, 6 hour, 9 hour, 12 hour, 18 hour, 24 hour, 30 hour, 36 hour and 48 hour after surgery.

Each patient in group D received $0.125 \%$ bupivacaine with $2 \mu \mathrm{gm}$. dexmedetomidine / ml solution through epidural catheter @ $4 \mathrm{ml} / \mathrm{hr}$. and group F received $0.125 \%$ bupivacaine with $2 \mu \mathrm{gm}$. fentanyl / ml solution through epidural catheter@ 4 $\mathrm{ml} / \mathrm{hr}$. just 15 minute after general anaesthesia.

Post-operative pain was assessed by visual analogue scale (VAS) which is a simple and often used method for evaluating variations in pain intensity. Subjects were instructed to indicate the intensity of the pain by marking a $10 \mathrm{~cm}$ line anchored with 
terms describing the extremes of pain intensity. VAS pain scale was $10 \mathrm{~cm}$ vertical lines anchored with "no pain" at the bottom and "worst imaginable pain" at the top. Visual analogue score (VAS) was recorded at 0 hour, 1 hour, 3 hour, 6 hour, 9 hour, 12 hour, 18 hour, 24 hour, 30 hour, 36 hour and 48 hour after surgery (VAS; $0-10 \mathrm{~cm} ; 0=$ no pain and $10=$ worst possible pain).

\section{Data Processing}

All data presented as mean (standard deviation) unless otherwise indicated. Analysis of variance unpaired student $\mathrm{t}$ test and chi-square test used to detect the demographic data among the two groups. Chi-square test, with any correction needed (e.g., Yates's continuity correction) used to analyze the collected data. Data collected on a predesigned data collection sheet and later on compiled on a master chart. A p value of $<0.05$ accepted as statistically significant. Statistical analysis carried out using Statistical Package for Social Science (SPSS) for Windows version 17.0.

\section{Results}

Eighty patients who underwent Hepatobilliary and pancreatic surgery were enrolled in the study. Among them 51 male and 29 female. Demographic data for each group was similar (Table 1). Sixteen patients (20\%) underwent Whipple's procedure, thirty six patients $(45 \%)$ underwent triple bypass \& twenty eight (35\%) patients underwent biliary reconstruction (Table 2). Mean duration of surgery for Whipple's procedure 4 hours, for Triple bypass 3.5 hours and for biliary reconstruction 3.12 hours (Table 2). The peroperative heart rate (Figure 1) and mean arterial blood pressure (Figure 2) decreased in both groups but the decrease was more in patients of dexmedetomidine group than fentanyl group and the comparison was significant between the groups $(\mathrm{p}<0.05)$.

In the postoperative period the heart rate (Table 3) and the mean arterial blood pressure (Table 4) were decreased in both groups but more decreased in group $\mathrm{D}$ that was dexmedetomidine group which was statistically significant $(\mathrm{p}<0.05)$.

Postoperative satisfaction with the epidural analgesia was similar with median scores of 69 (levobupivacaine) and 73(bupivacaine) (VAS; $100 \mathrm{~mm}=$ extremely satisfied) in the first 48 hour after operation (Figure 3). No statistical significant were observed in between groups $(\mathrm{p}>0.05)$

Total drug consumption for group D was $220 \mathrm{ml}$ and for group $\mathrm{F}$ was $260 \mathrm{ml}$. Additional drug was needed for group D $44 \mathrm{ml}$ and for group F $56 \mathrm{ml}$.

Table 5 showed that the postoperative complications like nausea and vomiting, pruritus, urinary retention and respiratory depression were significantly lower in dexmedetomidine group compared to fentanyl group $(p<0.05)$ and there was no significant difference in the incidence of headache or shivering between the two groups $(p>0.05)$.

Sixty patients Epidural catheter were inserted at the level of T8/9 out of which fourty two patients were group $\mathrm{D}$ and eighteen patients were group $\mathrm{F}$. In twenty patient Epidural catheter were inserted at the level of T9/10 out of which eight patients were in group D and twelve patients were in group F.

ASA catagorization (I, II) of group D was 30/12 and of group B was 22/16 patients. No cases of cardiac depression or central nervous system toxicity caused by vascular absorption or direct intravascular injection of local anaesthetic occurred. Our postoperative repeated visits for early detection of pain and provide increased patient satisfaction.

Table 1: Demographic variables

\begin{tabular}{lccc}
\hline Variables & Group-D & Group-F & p value \\
\hline Age (years) & $50.40 \pm 11.12$ & $52.20 \pm 12.55$ & $0.56^{\text {ns }}$ \\
Sex (M/F) & $26 / 14$ & $25 / 15$ & $0.78^{\text {ns }}$ \\
Weight (kg) & $65.30 \pm 9.44$ & $66.67 \pm 8.13$ & $0.55^{\text {ns }}$ \\
\hline
\end{tabular}

All values were presented as mean \pm SD or in frequencies. Data were analysed using unpaired student t-test. Statistically significance was set at pvalue $<0.05$. $(S=$ significance, $N S=$ not significant $)$ 
146 AKMMC J 2019:10(2)

Table 2: Distribution of the patients by type and duration of operation $(n=80)$

\begin{tabular}{lccc} 
Types of operation & Frequency & $\begin{array}{c}\text { Percentage (\%) } \\
\text { Duration of operation } \\
\text { (hours) Mean } \pm \text { SD }\end{array}$ \\
\hline Whilples & 16 & 45.0 & $4.0 \pm 1.12$ \\
Triple bypass & 36 & 35.0 & $3.5 \pm 0.85$ \\
Biliary reconstruction & 28 & 100.0 & $3.12 \pm 0.75$ \\
Total & 80 & & $3.54 \pm 0.60$ \\
\hline
\end{tabular}

All values were presented as mean $\pm S D$ or in frequencies. Data were analysed using unpaired student t-test. Statistically significance was set at pvalue $<0.05$. ( $S=$ significance, $N S=$ not significant $)$

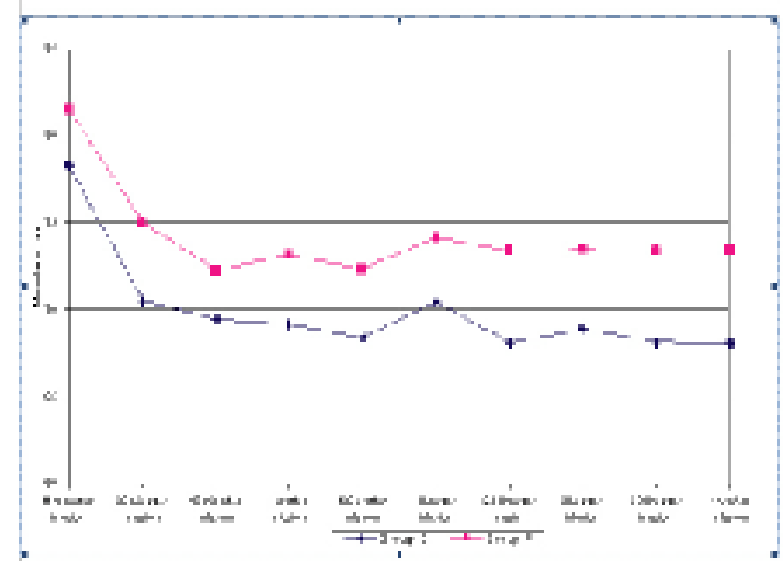

Figure- 2: Line diagram showing peroperative mean arterial blood pressure in two groups

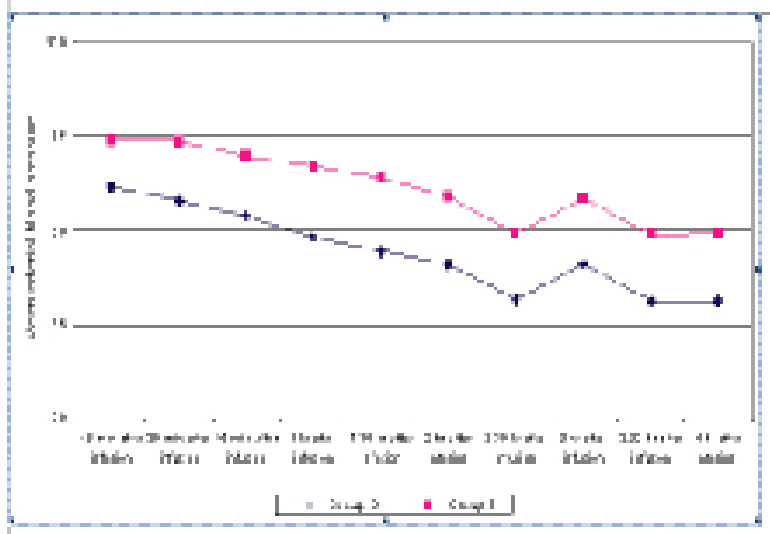

The mean arterial blood pressure at different time in peroperative period compared between two groups. Statistical significant were observed in between groups $(\mathrm{p}<0.05)$
R Ahmed, MSA Shaheen, PK Sarker et al.

Table 3: Comparison of heart rate at postoperative monitoring of the study respondents $(n=80)$

\begin{tabular}{lccc}
\hline Heart rate & $\begin{array}{c}\text { Group-D } \\
\text { Mean } \pm \text { SD }\end{array}$ & $\begin{array}{c}\text { Group-F } \\
\text { Mean } \pm \text { SD }\end{array}$ & p value \\
\hline 0 hr. immediate postoperative & $78.32 \pm 3.91$ & $81.62 \pm 3.02$ & $<0.001^{\mathrm{s}}$ \\
$1^{\text {st }}$ hour after infusion & $70.64 \pm 3.82$ & $75.14 \pm 7.12$ & $<0.001^{\mathrm{s}}$ \\
$3^{\text {rd }}$ hour after infusion & $68.52 \pm 6.72$ & $75.84 \pm 5.72$ & $<0.001^{\mathrm{s}}$ \\
$6^{\text {th }}$ hour after infusion & $69.54 \pm 5.42$ & $72.82 \pm 6.74$ & $<0.001^{\mathrm{s}}$ \\
$9^{\text {th }}$ hour after infusion & $68.46 \pm 4.33$ & $72.21 \pm 5.91$ & $<0.001^{\mathrm{S}}$ \\
$12^{\text {th }}$ hour after infusion & $69.82 \pm 4.19$ & $73.30 \pm 4.74$ & $<0.001^{\mathrm{S}}$ \\
$18^{\text {th }}$ hour after infusion & $70.56 \pm 3.94$ & $73.82 \pm 4.11$ & $<0.001^{\mathrm{S}}$ \\
$24^{\text {th }}$ hour after infusion & $69.84 \pm 4.21$ & $73.32 \pm 4.76$ & $<0.001^{\mathrm{s}}$ \\
$30^{\text {th }}$ hour after infusion & $68.15 \pm 3.75$ & $73.41 \pm 3.34$ & $<0.001^{\mathrm{S}}$ \\
$36^{\text {th }}$ hour after infusion & $67.38 \pm 3.24$ & $72.57 \pm 3.40$ & $<0.001^{\mathrm{s}}$ \\
$4^{\text {th }}$ hour after infusion & $68.74 \pm 3.10$ & $72.20 \pm 3.27$ & $<0.001^{\mathrm{s}}$
\end{tabular}

All values were presented as mean $\pm S D$ or in frequencies. Data were analysed using unpaired student t-test. Statistically significance was set at $\mathrm{p}$ value $<0.05$. $(\mathrm{S}=$ significance, $\mathrm{NS}=$ not significant $)$

The mean heart rate in postoperative period, were significantly higher in group $\mathrm{F}$ in compare with Group D $(\mathrm{p}<0.05)$.

Table 4: Comparison of mean arterial blood pressure at postoperative monitoring of the study respondents $(n=80)$

\begin{tabular}{lccc}
\hline $\begin{array}{l}\text { Mean arterial } \\
\text { pressure }\end{array}$ & $\begin{array}{c}\text { bloodGroup-D (n=40) } \\
\text { Mean } \pm \text { SD }\end{array}$ & $\begin{array}{c}\text { Group-F }(\mathbf{n}=40) \\
\text { Mean } \pm \text { SD }\end{array}$ & p value \\
\hline 0 hr. immediate postoperative & $92.33 \pm 7.60$ & $94.84 \pm 8.13$ & $0.001^{\mathrm{S}}$ \\
$1^{\text {th }}$ hour after infusion & $91.54 \pm 6.90$ & $94.67 \pm 7.84$ & $0.001^{\mathrm{S}}$ \\
$3^{\text {rd }}$ hour after infusion & $90.78 \pm 5.39$ & $93.92 \pm 6.55$ & $0.001^{\mathrm{S}}$ \\
$6^{\text {th }}$ hour after infusion & $90.72 \pm 5.35$ & $93.86 \pm 6.51$ & $0.001^{\mathrm{S}}$ \\
$9^{\text {th }}$ hour after infusion & $89.62 \pm 4.70$ & $93.39 \pm 4.36$ & $0.001^{\mathrm{S}}$ \\
$12^{\text {th }}$ hour after infusion & $88.86 \pm 3.95$ & $92.74 \pm 4.12$ & $0.001^{\mathrm{S}}$ \\
$18^{\text {th }}$ hour after infusion & $88.24 \pm 3.40$ & $91.76 \pm 4.10$ & $0.001^{\mathrm{S}}$ \\
$2^{\text {th }}$ hour after infusion & $89.30 \pm 4.57$ & $91.20 \pm 4.07$ & $0.001^{\mathrm{S}}$ \\
$3^{\text {th }}$ hour after infusion & $89.72 \pm 4.68$ & $92.46 \pm 4.50$ & $0.001^{\mathrm{S}}$ \\
$3^{\text {th }}$ hour after infusion & $88.88 \pm 3.95$ & $92.76 \pm 4.12$ & $0.001^{\mathrm{S}}$ \\
$4^{\text {th }}$ hour after infusion & $88.28 \pm 3.40$ & $91.80 \pm 4.10$ & $0.001^{\mathrm{S}}$ \\
\end{tabular}




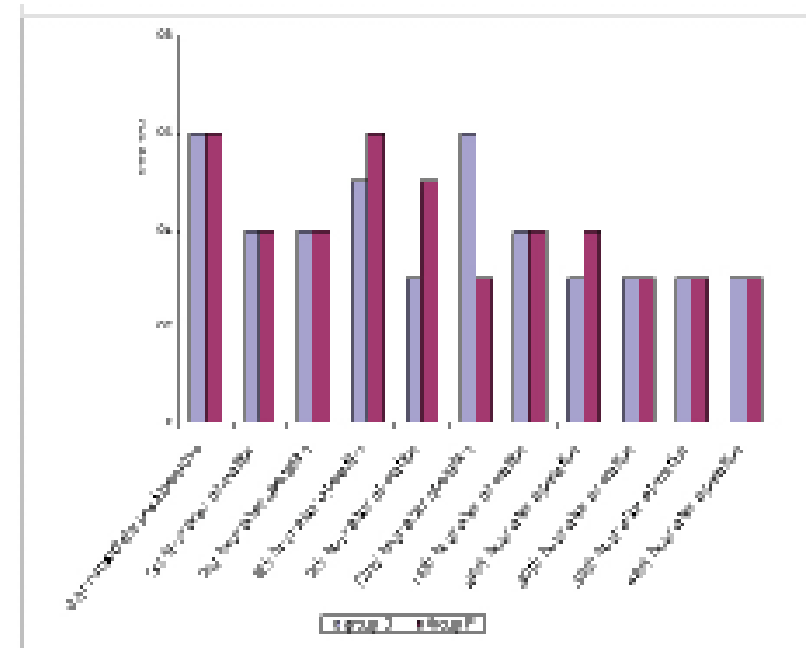

Figure-3: Line diagram showing postoperative VAS score in two groups

The mean VAS at postoperative period compared between two groups. No statistical significance were observed in between groups $(\mathrm{p}>0.05)$.

Table 5: Comparison of postoperative complications of the study respondents $(n=80)$

\begin{tabular}{lccc}
\hline Complications & $\begin{array}{c}\text { Group-D: Case Group-F: Control } \\
(\mathbf{n}=\mathbf{4 0 )}\end{array}$ & p value \\
& $(\mathbf{n}=\mathbf{4 0 )}$ & \\
\hline Nausea and vomiting & 04 & 12 & $<0.001^{\mathrm{S}}$ \\
Pruritis & 00 & 04 & $<0.001^{\mathrm{S}}$ \\
Respiratory depression & 00 & 04 & $<0.001^{\mathrm{S}}$ \\
Urinary retention & 00 & 05 & $<0.001^{\mathrm{S}}$ \\
Shivering & 02 & 04 & $0.57^{\mathrm{ns}}$ \\
Headache & 04 & 03 & $0.25^{\mathrm{ns}}$ \\
\hline
\end{tabular}

All values were presented as mean $\pm S D$ or in frequencies. Data were analysed using unpaired student t-test. Statistical significance was set at pvalue $<0.05$. $(\mathrm{S}=$ significance, $\mathrm{NS}=$ not significant $)$

\section{Discussion}

Epidural analgesia is considered as the gold standard analgesic technique for major abdominal surgeries. This strategy has the potential to provide complete analgesia and it is particularly effective at optimizing functional pain relief, thus improving patient satisfaction and postoperative outcome.
The use of well-documented physiological advantages of epidural analgesia in such a postoperative care program leads to decrease of morbidity across major abdominal procedures and significantly improves the quality of postoperative recovery. ${ }^{13,14}$

Findings of many clinical trials are relevant in this respect. Thus, patients with major abdominal procedures managed in a multimodal care program including epidural analgesia have demonstrated earlier discharge from intensive -care unit, earlier return of normal bowel function, reduced catabolism and less fatigue than those undergoing equivalent surgery but not participating in such a postoperative care program. ${ }^{15,13,16}$

In our study postoperative analgesia was prolonged significantly in the dexmedetomidine group and consequently the low dose consumption of local anaesthetic was used in dexmedetomidine group, and the same result was shown by other studies. ${ }^{17-20}$

The present study also showed that adding dexmedetomidine as an adjuvant to postoperative epidural bupivacaine $(0.125 \%)$ decreased the heart rate and the mean arterial blood pressure compared with fentanyl. ${ }^{1}$

These findings correlate with the result of other studies and the decrease in heart rate and mean arterial blood pressure can be explained by the central action of dexmedetomidine in decreasing the sympathetic outflow and catecholamines release. ${ }^{21,22}$ Eskander et al. ${ }^{23}$ found that the heart rate decreased significantly with dexmedetomidine, but the mean arterial blood pressure decreased significantly in the control group compared to dexmedetomidine.

The incidence of sedation before opioid administration was higher in dexmedetomidine compared to fentanyl group, but after opioid administration it was higher in the fentanyl group compared to dexmedetomidine group, and this may be related the sedative effects of opioids required in the fentanyl group more than dexmedetomidine group. Eskander et $a .^{23}$ showed the same result in spite of the required nalbuphine was higher in the control group and the same result was found by Kurr et al. ${ }^{17}$ and Gupta et al. ${ }^{25}$ 
The side effects such as nausea, and vomiting, pruritis, urinary retention, and respiratory depression were significantly lower in dexmedetomidine group compared to fentanyl group and a similar result was shown by Gupta et al. ${ }^{23}$ Bajwa et al. ${ }^{24}$ found that nausea and vomiting was associated with epidural fentanyl more than dexmedetomidine and no difference in the incidence of pruritis, respiratory depression or urinary retention between the two groups.

\section{Conclusion}

Dexmedetomidine is an ideal adjuvant to epidural bupivacaine for postoperative analgesia compared to fentanyl in patients undergoing hepatobiliary pancreatic surgery. Dexmedetomidine provides a better postoperative analgesia and reduces the postoperative opioids related complications compared to fentanyl.

\section{Conflict of interest: None.}

\section{References}

1. Morgan GE, Mikhall MS \& Murray MJ, In: Clinical anaesthesiology, Lange Medical Books/ Mc Graw-Hill, 2006; 361

2. Dahl JL, Gordon D, Ward S. Institutionalizing pain management: The postoperative pain management quality improvement Project. J Pain 2003; 4: 361-71

3. Warfield CA, Kahn CH.Acute pain management programs in U.S. Hospitals and experiences and attitudes among U.S adults. Anaesthesiology 1995; 83: 1090-94

4. Apfelbaum JL, Chen C, Mehta SS, et al. aljaostoperative pain experience: Results from a national survey suggests postoperative pain continues to be undermanaged.Anesth ANALG 2003; 97: 534-40

5. Huang $\mathrm{N}$, CunningghamF, Laurito $\mathrm{CE}$, Chen C:Can we do better with postoperative pain management. Am J Surg 2001; 182: 440-8

6. Elia N, Lyskowski C, Tramer MR. Does multimodal analgesia with acetaminophen, nonsteroidal anti-inflammatory drugs, or selective cyclooxygenase-2 inhibitors and patient -controlled analgesia morphine offer advantages over morphine alone? Meta analyses of ramdomized trials. Anesthesiol. 2005; 103(6): 1296-304

7. Schug SA, Manopis A. Update on the role of non-opioids for postoperative pain treatment. Best Pract Res Clin Anaesthesiol.2007; 21(1): 15-30

8. Benzon HT, Wong HY, Belavic AM, et al. A randomized double blind comparison of epidural fentanyl infusion versus patient controlled analgesia with morphine for postthoracotomy pain. Anesth Analg. 1993; 76: 316-22 [Pub Med]

9. Maze M, Scarfini C and Cavaliere F. New agents for sedation in the intensive care unit. Crit Care Clin. 2001; 17: 881-97. | PubMed

10. Esmaoglu A, Mizrak A, Akin A, et al. Addition of dexmedetomidine to lidocaine for intravenous regional anaesthesia. Eur J Anaesthesiol. 2005; 22: 447-51 | Article | PubMed

11. Venn RM, Hell J, Grounds RM. Respiratory effects of dexmedetomidine in the surgical patient requiring intensive care. Crit Care. 2000; 4: 302-8 [PMC free article] [PubMed]

12. Bloor BC, Abdul-Rasool I, Temp J, et al. The effects of medetomidine, an alpha2-adrenergic agonist, on ventilatory drive in the dog. Acta Vet scand Suppl. 1989; 85: 65-70. [PubMed]

13. Maheshwari AV, Blum YC, Shekhar L, et al. Multimodal pain management after total hip and knee arthroplasty at the Ranawat Orthopaedic Center. Clin Orthop Relat Res 2009; 467(6): 1418-23

14. Prakash S, Fatima T, Pawar M, Patient control analgesia with fentanyl for burn dressing changes. Anesth Analg 2004; 99(2): 552-5, table.

15. Nimmo, S. (2004). Benefit and outcome after epidural analgesia. Continuing Education in Anaesthesia, Critical care \& Pain, Vol. 4, No. 2, (April 2004), pp. 44 - 47, ISSN 1743 - 1824.

16. Carli, F.; Mayo, N. \& Klubien, K. (2002). Epidural analgesia enhances functional exercise 
capacity and health related quality of life after colonic surgery: results of a randomized trial. Anesthesiology, Vol. 97, No. 3, (September 2002), pp. 540 - 549, ISSN 0003 - 3022.

17. Kaur s, Attri JP, Kaur G and Singh TP. Comparative evaluation of ropivacaine versus dexmedetomidine and ropivacaine in epidural anesthesia in lower limb orthopedic surgeries. Saudi j Anaesth. 2014; 8: 463-9. | Article | PubMed Abstract | PubMed FullText

18. Gupta K, Bhawna Rastogi B, Gupta PK, et al. epidural $0.5 \%$ levobupivacaine with dexmedetomidine versus fentanyl for vaginal hysterectomy: a prospective study. Indian J Pain. 2014; 28: 149-54. | Article

19. Akin S, Aribogan A and Arslan G. Dexmedetomidine as an adjunct to epidural analgesia after abdominal surgery in elderly intensive care patients: a prospective, doubleblind, clinical trial. Curr Ther Res Clin Exp. 2008; 69:16-28. |article | PubMed Abstract | PubMed FullText

20. Elhakim m, Abdelhamid D, Abdelfattach H, et al. Effect of epidural dexmedetomidine on intraoperative awareness and postoperative pain after one-lung ventilation. Acta Anaesthesiol Scand. 2010; 54: 703-9. | Article | PubMed
21. Bajwa SJ, Bajwa SK, Kaur J, Singh G, Arora V, Gupta S, Kulshrestha A, Singh A, Parmar S and Gorya S. Dexmedetomidine and clonidine in epidural anaesthesia: A comparative evaluation. Indian J Anaesth. 2011; 55: 116-21. | Article | PubMed Abstract | PubMed Full Text

22. Saadawy I, Boker A, Elshahawy MA, et al. Effect of dexmedetomidine on the characteristics of bupivacaine in a caudal block in paediatrics. Acta Anaesthesiol Scand. 2009; 53: 251-6. Article | PubMed

23. Eskander AM and Ebeid AM. Effects of epidural dexmedetomidine and low-volume bupivacaine on postoperative analgesia after total knee replacement. Ain-Shams J Anaesthesiol. 2014; 7: 193-7. | Article

24. Bajwa SJ, Arora V, Kaur J, et al. Comparative evaluation of dexmedetomidine and fentanyl for epidural analgesia in lower limb orthopedic surgeries. Saudi J Anaesth. 2011; 5: 365-70. | Article | PubMed Abstract | PubMed Full Text

25. Gupta S, Saluja N, Goyal P and Choudhary B. A comparative Evaluation of Levobupivacaine Hydrochloride with Dexmedetomidine in Epidural Anesthesia and Postoperative Pain Relief undergoing infraumbilical Surgeries. MGM J Med Sci. 2015; 2: 78-82 